This is the supplementary material associated with the article

\title{
Dynamic Intermediate Profiles of Zeolite catalyzed Methanol to Olefins Revealed by Reactive Molecular Dynamics
}

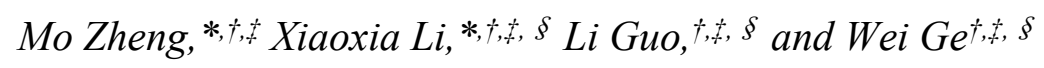

$\dagger$ State Key Laboratory of Multiphase Complex Systems, Institute of Process Engineering, Chinese Academy of Sciences, Beijing 100190, China

Innovation Academy for Green Manufacture, Chinese Academy of Sciences, Beijing 100190, China $\S$ School of Chemical Engineering, University of Chinese Academy of Sciences, Beijing 100049, China Corresponding Author

*Phone: 86-10-82544936. Fax: 86-10-82544945. E-mail: mzheng@ipe.ac.cn.

*Phone: 86-10-82544944. Fax: 86-10-82544945. E-mail: xxia@ipe.ac.cn 


\section{Supplementary Materials S1}

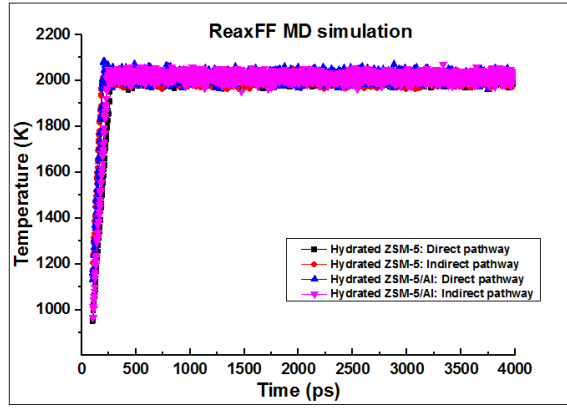

a

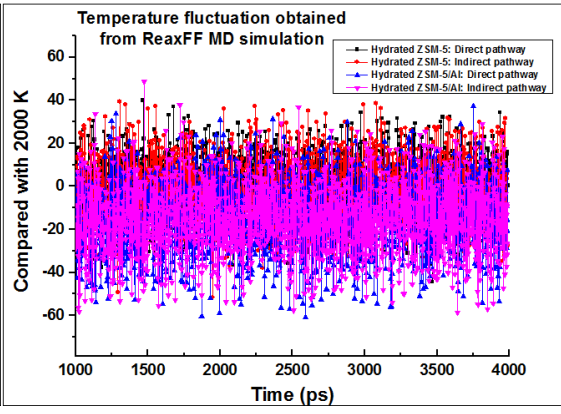

$\mathrm{b}$

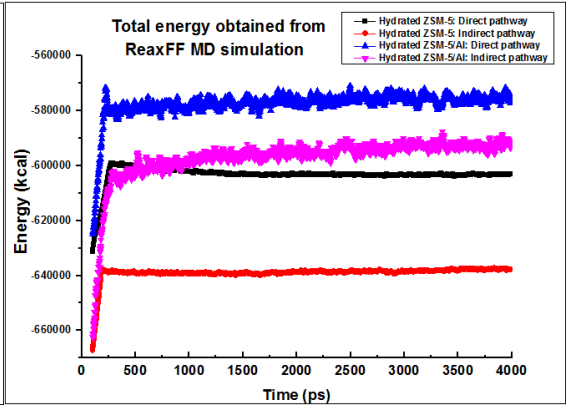

c

Figure S1. Evolving tendencies of temperature and energy with time obtained from ReaxFF MD for MTO process containing $\mathrm{CH}_{3} \mathrm{OH}$ and $\mathrm{H}_{2} \mathrm{O}$ as reactants (direct pathway) and containing $\mathrm{C}_{12} \mathrm{H}_{18}, \mathrm{CH}_{3} \mathrm{OH}$ and $\mathrm{H}_{2} \mathrm{O}$ as reactants (indirect pathway) at $2000 \mathrm{~K}$ 


\section{Supplementary Materials S2}

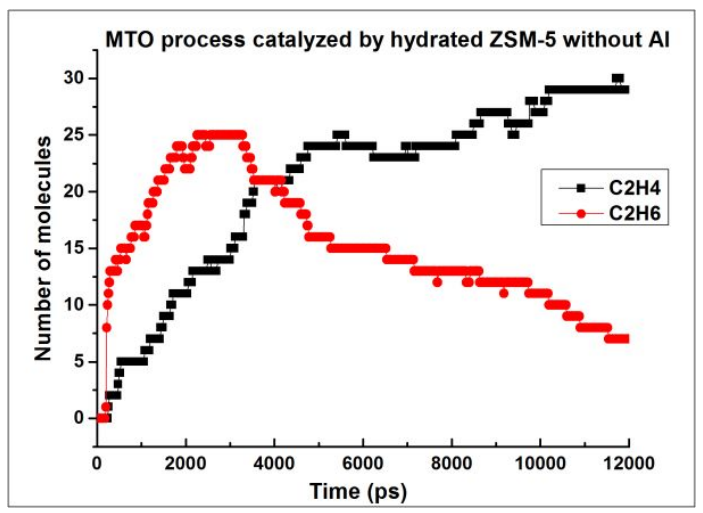

Figure S2. Evolving trends of $\mathrm{C}_{2} \mathrm{H}_{4}$ and $\mathrm{C}_{2} \mathrm{H}_{6}$ with time obtained from a very long time ReaxFF MD simulation of $12 \mathrm{~ns}$ for MTO process catalyzed by hydrated ZSM-5 with $\mathrm{CH}_{3} \mathrm{OH}$ and $\mathrm{H}_{2} \mathrm{O}$ as reactants at $2000 \mathrm{~K}$ 


\section{Supplementary Materials S3}

The activation in Table 2 of the manuscript refers to bond breaking and forming of molecules taking place on zeolites. The analysis strategy for categorizing the involved activation reactions of C-H, H-O, C-O and $\mathrm{CH}_{3} \mathrm{O}$ includes several steps. The first step is to pick the reactions with zeolite structures from the reaction list of 10,000 reactions to built a sub-list of "zeolite-involved" reactions. Subsequently, the reactive sites to generate $\mathrm{H}-\mathrm{O}, \mathrm{C}-\mathrm{H}, \mathrm{CH}_{3} \mathrm{O}$ both for bond breaking and forming were searched with the aid of VARxMD to generate $\mathrm{H}-\mathrm{O}, \mathrm{C}-\mathrm{H}, \mathrm{CH}_{3} \mathrm{O}$ activation reactions. To discriminate the $\mathrm{C}-\mathrm{O}$ bond in $\mathrm{CH}_{3} \mathrm{O}$, the searching of reactive sites to generate $\mathrm{C}-\mathrm{O}$ bond (in Table 2) for bond breaking and forming was performed first and then the overmap part of $\mathrm{C}-\mathrm{O}$ bond in $\mathrm{CH}_{3} \mathrm{O}$ was removed. 